\title{
Uncommon presentation of septo-optic dysplasia:
} case report

\begin{abstract}
Septo-optic dysplasia (SOD) is a rare developmental disorder with an incidence of 1 in $10,000 .{ }^{1}$ It comprises of clinical trial of midline brain abnormality, optic nerve hypoplasia and hypopituitarism. Diagnosis of this syndrome is clinical with equal occurrence rate in both the sexes.However in recent times various genetic mutations have been found causing this syndrome complex like $\mathrm{HESX}_{1}, \mathrm{OTX}_{2}, \mathrm{SOX}_{3}$ and $\mathrm{SOX}_{2}$, at the same time yield of genetic diagnosis in less than $1 \%$.We report here two unique cases of Septo-optic dysplasia, first with late presentation with multiple pituitary hormone deficiency and the second with normal pituitary functions and associated infantile obesity.
\end{abstract}

Volume 4 Issue 5 - 2017

\author{
Mudita Dhingra \\ Department of Paediatric Endocrinology, India
}

Correspondence: Mudita Dhingra, Department of Paediatric Endocrinology, Radhakishan Hospital, Kurukshetra (Haryana), India,Email drmudita I@gmail.com

Received: March 14, 2017 | Published: May 23, 2017

Keywords: septum pellucidum, hypopituitarism, optic atrophy, dysplasia, syndrome, hypoglycaemia, neonatal period

Abbreviations: SOD, septo-optic dysplasia; HESX, homeobox gene expressed in es cells; $\mathrm{OTX}_{2}$, orthodenticle homeobox 2; $\mathrm{SOX}_{3}$, sry-related hmg box gene 3: MRI, magnetic resonance imaging; AML, angiomyolipoma

\section{Case report}

\section{Case I}

11 year 10 month old prepubertal female, belonging to Sikh community, born of non-consanguineous union presented in the paediatric endocrine clinic with complains of short stature. She was born at full term by vaginal delivery and her birth weight was $2.5 \mathrm{kgs}$. There was no history of prolonged jaundice or hypoglycaemia in neonatal period. Her motor milestones were delayed. Dentition started at 2 years of age and deciduous tooth shed at 10 years of age. On enquiry there was also history of nocturia since 8 years of age. She was doing well in school and there were no behavioural problems. Family history was non-contributory. On examination her weight was $22 \mathrm{kgs}$ ( $Z$ score-3.9), height of $119 \mathrm{cms}$ ( $Z$ score -4.1$)$ with bone age of 7 years. She had phenotypic features of growth hormone deficiency in form of infantile voice, midfacial crowding and preserved truncal fat. She also had esotropia and nystagmus in left eye. On complete opthalmological examination she had left eye amblyopia with optic atrophy. Anosmia was also present. Hormonal evaluation showed normal free $\mathrm{T}_{4}(0.94 \mathrm{ng} / \mathrm{dl})$, Serum cortisol $(9 \mathrm{ug} / \mathrm{dl})$ and Serum prolactin $(16 \mathrm{ng} / \mathrm{ml})$. Her Peak GH level on clonidine stimulation was $0.6 \mathrm{ng} / \mathrm{ml}$. Serum sodium was $147 \mathrm{mEq} / \mathrm{L}$ with low urine osmolality of $93 \mathrm{mOsm} / \mathrm{L}$ and serum osmolarity of $301 \mathrm{mOsm} / \mathrm{L}$. Hence she was diagnosed with multiple pituitary hormone deficiency (Growth hormone and Antidiuretic Hormone) .MRI Pituitary and brain showed absence of septum pellucidum, small pituitary gland with partially empty sella turcica. Posterior pituitary bright spot was not seen and there was absence of olfactory bulb. Rest of the parenchyma was normal. Hence she was started on Growth hormone therapy and desmopressin and planned for periodic surveillance for other pituitary hormone deficiency.

\section{Case 2}

2 years old male, product of non-consanguineous union presented with rapid gain in weight, not recognising parents and surroundings and global developmental delay and behavioural problems in our clinic. Birth history was uneventful apart from physiological jaundice. There was no history of seizures, polyuria and temperature instability. On examination his weight was $24 \mathrm{kgs}(Z$ score +5.47 ), length was $89.5 \mathrm{cms}$ with BMI of $30.3 \mathrm{~kg} / \mathrm{m}^{2}$. He had mild dysmorphism in form of epicanthic fold, low set ears and depressed nasal bridge. Opthalmological examination showed right eye squint and nystagmus (Figure 1-4). Fundus showed optic disc hypoplasia (Right $>$ Left). Hormonal evaluation showed normal free $T_{4}(1 \mathrm{ng} / \mathrm{dl})$, Serum cortisol -12.5ug/dl, Serum prolactin - 22ng/ml. Fasting blood glucose, electrolytes and lipid profile were normal. In view of global developmental delay and optic atrophy neuroimaging was performed with showed absence of septum pellucidum, hence confirming the diagnosis. He was managed with lifestyle modification, behavioural therapy and regular monitoring for endocrinopathies.

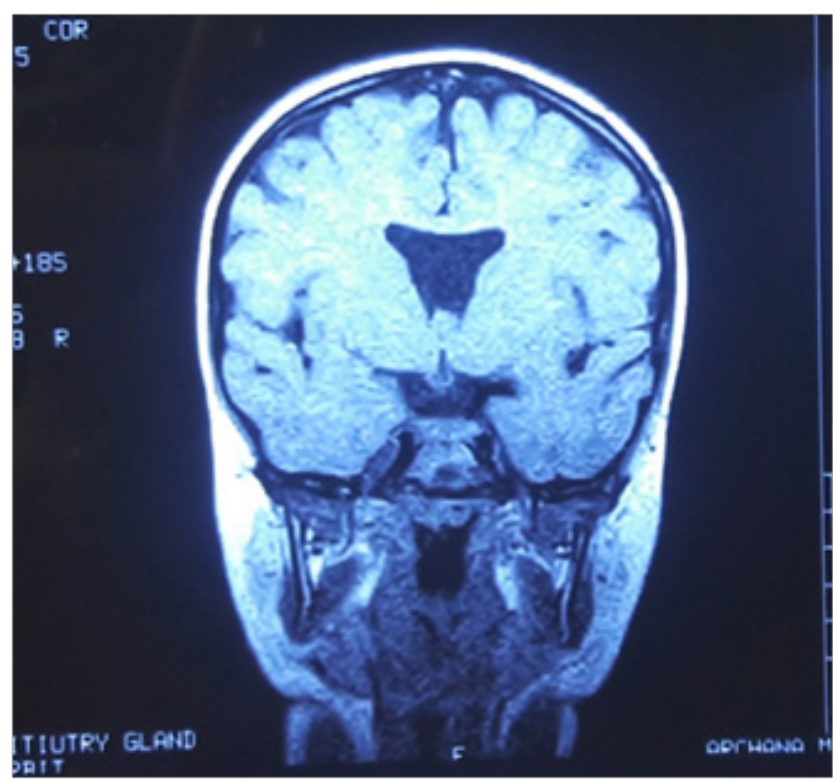

Figure I Coronal section of MRI Brain showing absent septum pellucidum (Thin arrow) and hypoplastic pituitary (Bold arrow). 


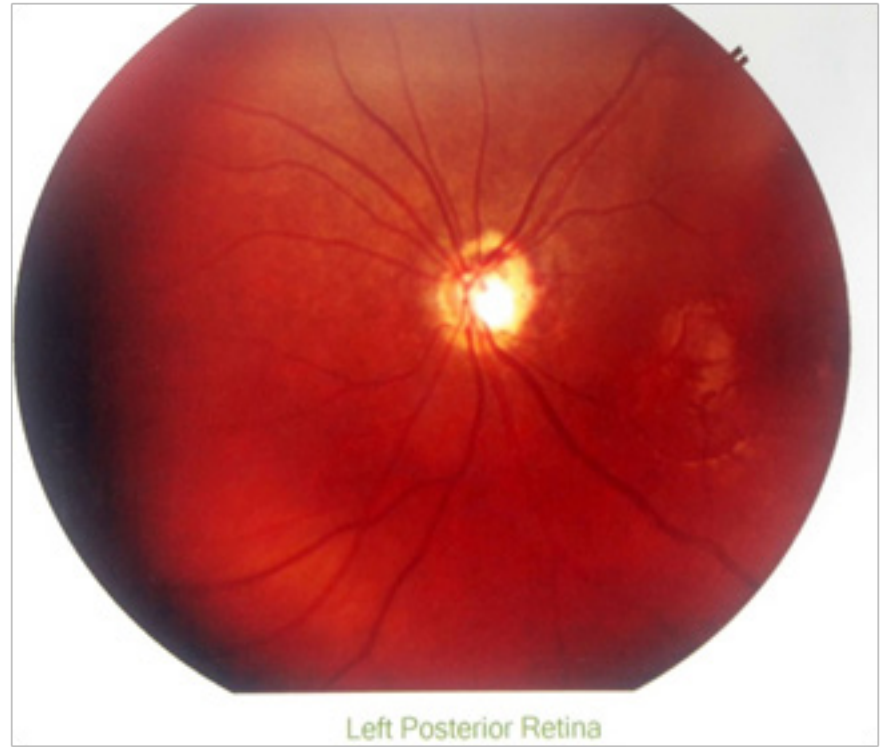

Figure 2 Left retina of patient showing peripapilary atrophy and double ring sign.

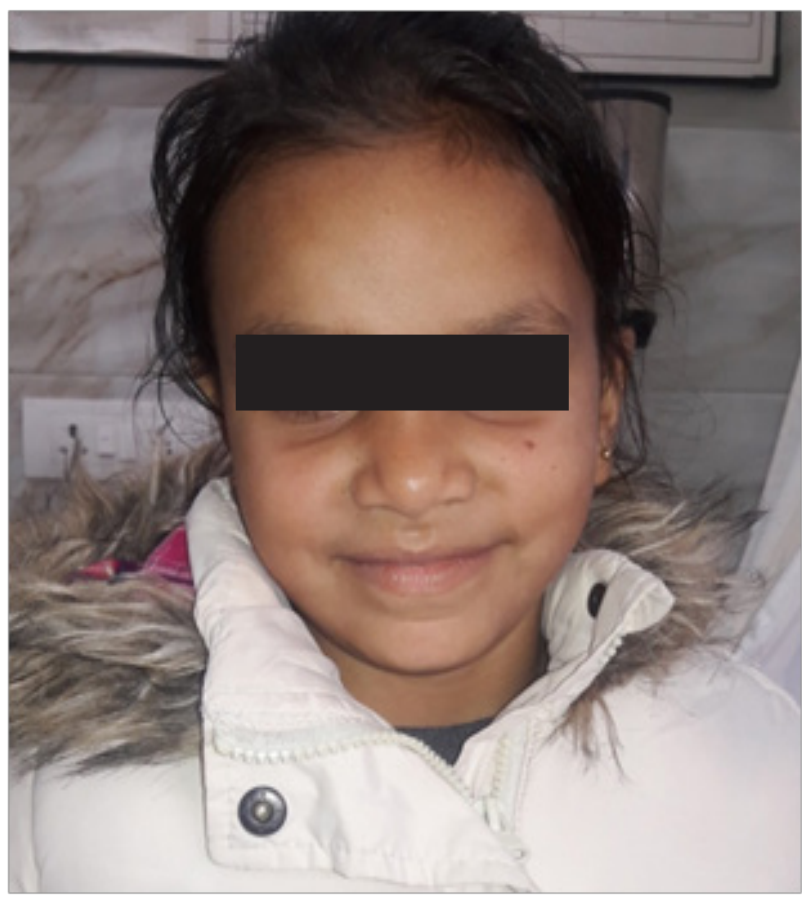

Figure 3 Clinical photograph (Case I) showing facial features of growth hormone deficiency and squint in left eye.

\section{Discussion}

Septo-optic dysplasia (SOD), also known as De Morsier's syndrome $^{2}$ is a rare and unique form of hypopituitarism in children. It was first explained by Reeves in 1941 according to the parallel lack of septum pellucidum in patients with optic nerve disorder. Its incidence is 1 in 10,000 live births with equal predilection in both sexes. Both genetic and environmental factors play a role in its occurrence. It comprises of clinical trial of absence of the septum pellucidum, congenital optic nerve dysplasia, and hypopituitarism which occurs in almost $30 \%$ of patients. ${ }^{3}$ Presence of two of three criteria forms atypical form of SOD. This syndrome is more common in children born of young nullipara woman and in areas with high unemployment rate. Cocaine or alcohol abuse during pregnancy is also postulated to be one of the etiological factors. ${ }^{4}$ Two major theories have been described: Developmental theory which suggests teratogenic injury to the fetus at around 6 weeks interferes with normal development of retinal ganglion cells, hypothalamus and septum pellucidum and Destructive theory which explains damage to already formed retinal pathway during any part of gestation. Genes such as $\mathrm{HESX}_{1}, \mathrm{SOX}_{2}$ and $\mathrm{SOX}_{3}$ are responsible for occurrence of familial cases. ${ }^{5}$ Various developmental malformations have been described like corpus callosal agenesis, schizencephaly, Holoprosencephaly, Duane syndrome, blepharophimosis, hemifacial atrophy, anopthalmia, olfactory tract agenesis (as present in case 1 ) , autism, pineal gland cyst ${ }^{6}$ and arachnoid cyst. $^{7}$ Other rare associations reported are congenital hepatic fibrosis, renal angiomyolipoma $(\mathrm{AML})^{8}$ cerebral cortical abnormality (SOD plus $)^{9}$ and transverse limb defect. ${ }^{10}$ Neurological abnormalities can also occur in patients like cerebral palsy, developmental delay or seizures.

The most common endocrine abnormality are high prolactin level and growth hormone deficiency (73\% and 58\% respectively) followed by central hypothyroidism (39\%) and adrenal insufficiency (31\%) and also gonadotropin deficiency. On the other hand they can also have precocious puberty due to hypothalamic damage which may mask growth hormone deficiency. Pituitary affection in these patients can occur at any age and needs long term surveillance to prevent from life threatening adrenal crisis. These can vary from single hormone deficiency or other pituitary hormone deficiency occurring gradually over time. Diabetes insipid us leading to hypernatremia, thermal dysregulation and ACTH deficiency are important causes of sudden death in these patients. Many children may become obese due to hypothalamic involvement.

Neurologically these children can be intellectually disabled because of brain malformations and visual deficit. An adequate and timely rehabilitation program can play a vital role in promoting neuropsychomotor development. In contrast, according to other reviews, ${ }^{11}$ patients with SOD-plus seemed to have a more favourable cognitive profile, but greater risk of major neurological involvement. Neuroimaging in SOD Midline abnormalities include a variety of abnormalities like agenesis of corpus callosum, absence of the septum pellucidum, cerebellar hypoplasia, aplasia of the fornix and schizencephaly. The magnetic resonance imaging (MRI) findings are heterogeneous including morphological anomalies of the cortex and malrotation of the hippocampus. Neuroradiological anomalies are present in up to $75-80 \%$ of the patients with optic nerve hypoplasia. Ectopic posterior pituitary predicts the existence of hypopituitarism, while hemispheric migration anomalies are predictors of neurodevelopment deficits. ${ }^{13}$

Ophthalmologists and neurologists should be aware to identify any of the features of the syndrome, and timely refer to paediatric endocrinologist, since the pituitary deficiencies may be present since the neonatal period or can appear throughout life, which can lead to permanent sequelae.

\section{Consent}

Informed and written consent has been obtained by patient's relative. 


\section{Acknowledgements}

None.

\section{Conflicts of interest}

The author declares there is no conflict of interest.

\section{References}

1. Ferran KD, Paiva IA, Gilban DL, et al. Septo-optic dysplasia. Arq Neuropsiquiatr. 2010;68(3):400-405.

2. DE Morsier G. Studies on malformation of cranio-encephalic sutures. III. Agenesis of the septum lucidum with malformation of the optic tract. Schweiz Arch Neurol Psychiatr. 1956;77(1-2):267-292.

3. Morishima A, Aranoff GS. Syndrome of septo-optic-pituitary dysplasia: the clinical spectrum. Brain Dev. 1986;8(3):233-239.

4. Garcia Filion P, Borchert M. Optic nerve hypoplasia syndrome: a review of the epidemiology and clinical associations. Curr Treat Options Neurol. 2013;15(1):78-89.

5. Kelberman D, de Castro SC, Huang S, et al. SOX 2 plays a critical role in the pituitary, forebrain and eye during human embryonic development. J Clin Endocrinol Metab. 2008;93(5):1865-1873.
6. Ng Hong Kee, Yaakub Azhany, Zunaina Embong, et al. Septo-optic Dysplasia with Pineal Gland Cyst . J Med Case Rep. 2015;3(3):233236.

7. Lyons $\mathrm{C}$, Castano $\mathrm{G}$, Jan JE, et al. Optic nerve hypoplasia with intracranial arachnoid cyst. J AAPOS. 2004;8(1):61-66.

8. Cichocki M, Sosnowski M, Jablonowski Z. A giant renal angiomyolipoma (AML) in a patient with septo-optic dysplasia (SOD). Eur J Med Res. 2014;19:46.

9. Zoric L, Nikolic S, Stojcic M, et al. Septo-optic dysplasia plus: a case report. BMC Research Notes. 2014;7:191.

10. Millar S, Chillingworth A, Bell A, et al. Septo-optic dysplasia with a transverse limb defect. Clin Dysmorphol. 2008;17(2):155-156.

11. Signorini SG, Decio A, Fedeli C, et al. Septo-optic dysplasia in childhood: the neurological, cognitive and neuro-ophthalmological perspective. Dev Med Child Neurol. 2012;54(11):1018-1024.

12. Haddad NG, Eugster EA. Hypopituitarism and neurodevelopmental abnormalities in relation to central nervous system structural defects in children with optic nerve hypoplasia. J Pediatr Endocrinol Metab. 2005;18(9):853-858. 